INTESTINAL MICROFLORA

\title{
Dietary fructo-oligosaccharides and inulin decrease resistance of rats to salmonella: protective role of calcium
}

\author{
S J M Ten Bruggencate, I M J Bovee-Oudenhoven, M L G Lettink-Wissink, M B Katan, \\ $R$ Van der Meer
}

See end of article for authors' affiliations

.....................

Correspondence to: Dr I M J BoveeOudenhoven, Wageningen Centre for Food Sciences/NIZO Food Research, PO Box 20, 6710 Ede, the Netherlands; ingeborg.bovee@NIZO.nl

Accepted for publication 22 October 2003
Background: We have shown recently that rapid fermentable fructo-oligosaccharides (FOS) decreased resistance of rats towards salmonella. It is not known whether inulin (which is fermented more gradually) has similar effects or whether buffering nutrients can counteract the adverse effects of rapid fermentation. Aims: To compare the effects of dietary inulin and FOS on resistance of rats to Salmonella enterica serovar Enteritidis and to determine whether calcium phosphate counteracts the effects of fermentation.

Methods: Male Wistar rats ( $\mathrm{n}=8$ per group) were fed a human "Western style diet". Diets with $60 \mathrm{~g} / \mathrm{kg}$ cellulose (control), FOS, or inulin had either a low $(30 \mathrm{mmol} / \mathrm{kg})$ or high $(100 \mathrm{mmol} / \mathrm{kg})$ calcium concentration. After an adaptation period of two weeks, animals were orally infected with $2 \times 10^{9}$ colony forming units of Salmonella enterica serovar Enteritidis. Colonisation of salmonella was determined by quantification of salmonella in caecal contents. Translocation of salmonella was quantified by analysis of urinary nitric oxide metabolites in time.

Results: Inulin and FOS decreased intestinal pH and increased faecal lactobacilli and enterobacteria. Moreover, both prebiotics increased the cytotoxicity of faecal water and faecal mucin excretion. Both prebiotics increased colonisation of salmonella in caecal contents and enhanced translocation of salmonella. Dietary calcium phosphate counteracted most of the adverse effects of inulin and FOS.

Conclusions: Both inulin and FOS impair resistance to intestinal infections in rats. This impairment is partially prevented by dietary calcium phosphate. The results of the present study await verification in other controlled animal and human studies.
G astrointestinal infections induced by food borne pathogens are a major clinical problem. ${ }^{1}$ Survival of food borne pathogens within the intestinal tract can potentially be modulated by dietary prebiotics. Prebiotics, which include fructo-oligosaccharides (FOS) and inulin, are defined as non-digestible food ingredients that beneficially affect the host by selectively stimulating the growth and/or activity of one or a limited number of bacteria in the colon that can improve the health of the host. ${ }^{2}$ Stimulation of the endogenous microflora by dietary prebiotics ${ }^{3}{ }^{4}$ may inhibit colonisation of intestinal pathogens by production of organic acids and by competing for nutrients and mucosal adhesion sites. ${ }^{5}$ However, we showed previously that FOS decreases the resistance towards the invasive food borne pathogen Salmonella enterica serovar Enteritidis. ${ }^{67}$ Rapid fermentation of FOS by the intestinal microflora may lead to high luminal concentrations of organic acids. These organic acids may induce damage to the mucosal barrier ${ }^{8}$ and hence decrease resistance to intestinal pathogens.

Both inulin and FOS are composed of linear chains of fructose units, linked by $\beta(2-1)$ bonds and often terminated by a glucose unit. The number of fructosyl moieties ranges from 2 to 60 for inulin and from 2 to 7 for FOS. In vitro, fermentation experiments revealed that molecules with a degree of polymerisation (DP) $>10$ are fermented, on average, half as quickly as molecules with a DP of $<10 .^{10}$ Thus the possible adverse consequences of rapid fermentation might be more pronounced with FOS than with inulin.

The consequences of excessive fermentation can potentially be inhibited by dietary calcium phosphate. Calcium forms an insoluble complex with phosphate in the upper small intestine. ${ }^{11}$ This complex increases the buffering capacity throughout the intestinal lumen. ${ }^{912}$ Thus it can be speculated that dietary calcium phosphate counteracts the effects of rapid fermentation of inulin and FOS.

The aim of the present study was to compare the effects of FOS and inulin on the resistance of rats to the invasive pathogen Salmonella enterica serovar Enteritidis. In addition, we determined whether dietary calcium phosphate can counteract the effects of rapid fermentation.

\section{METHODS}

Diets, infection, and dissection of the animals

The animal welfare committee of Wageningen University and Research Centre (Wageningen, the Netherlands) approved the experimental protocol. Specific pathogen free male Wistar rats (WU, Harlan, Horst, the Netherlands), eight weeks old, with a mean body weight of 276 (2) g, were housed individually in metabolic cages. All animals were kept in a temperature $\left(22-24^{\circ} \mathrm{C}\right)$ and humidity $(50-60 \%)$ controlled environment in a 12 hour light-dark cycle. Animals $(n=8$ per diet group) were fed restricted quantities ( $13 \mathrm{~g} /$ day; $266 \mathrm{~kJ} /$ day) of a purified diet. Restricted food intake was necessary to prevent differences in food consumption and hence differences in vitamin and mineral (especially calcium) intake. The control diet contained (per kg) $200 \mathrm{~g}$ acid casein, $552 \mathrm{~g}$ glucose, $160 \mathrm{~g}$ palm oil, $40 \mathrm{~g}$ corn oil, $20 \mathrm{~g}$ cellulose, $49 \mathrm{~g}$ mineral mix (without calcium), and $14 \mathrm{~g}$ vitamin mix according to AIN93 recommendation. ${ }^{13}$ The experimental diets were supplemented with $60 \mathrm{~g} / \mathrm{kg}$ cellulose (Arbocel type

Abbreviations: CFU, colony forming units; DP, degree of polymerisation; FOS, fructo-oligosaccharides; ICP-AES, inductively coupled plasma-atomic emission spectrophotometry; $\mathrm{NO}_{x}$, sum of nitrate and nitrite; PCR, polymerase chain reaction 
B800; JRS, Zutphen, the Netherlands), inulin (purity 99\%, Frutafit TEX!; Sensus, the Netherlands), or FOS (purity 93\%, Raftilose P95; Orafti, Tienen, Belgium). Calcium (30 or $100 \mathrm{mmol} \mathrm{CaHPO}_{4} \cdot 2 \mathrm{H}_{2} \mathrm{O} / \mathrm{kg}$ diet; Merck, Darmstadt, Germany) was added at the expense of glucose. The final calcium content of the diets was measured by inductively coupled plasma-atomic emission spectrophotometry (ICPAES; Varian, Mulgrave, Australia) and was 38, 34, and $34 \mathrm{mmol} / \mathrm{kg}$ for the low calcium/control, inulin, and FOS diets, respectively. Calcium contents of the high calcium/ control, inulin, and FOS diets were 111, 114, and $107 \mathrm{mmol} / \mathrm{kg}$, respectively. Demineralised drinking water was consumed ad libitum. Animals were acclimatised to the housing and dietary conditions for two weeks. Subsequently, animals were orally infected by gastric gavage with $1 \mathrm{ml}$ of saline containing $30 \mathrm{~g} / \mathrm{l}$ sodium bicarbonate and $2 \times 10^{9}$ colony forming units (CFU) of Salmonella enterica serovar Enteritidis (clinical isolate, phage type 4 according to international standards; B124l culture of NIZO Food Research, Ede, the Netherlands). The virulence of this strain is sustained by routine oral passage in Wistar rats, followed by isolation of translocated salmonella from the liver and spleen. Salmonella were cultured and stored, as described previously. ${ }^{12}$ At day 7 after infection, rats were killed by carbon dioxide inhalation.

\section{Microbiological analyses of faeces}

Faeces were quantitatively collected and pooled per animal for five days before salmonella infection. Faeces were freeze dried and subsequently ground to obtain homogeneous powdered samples. Real time quantitative polymerase chain reaction (PCR), targeting a $110 \mathrm{bp}$ transaldolase gene sequence, was used to specifically quantify bifidobacteria in faecal samples, as described and validated previously. ${ }^{6}{ }^{14}$ The cycle threshold values generated by real time PCR from DNA extracts of dilutions of suspensions of Bifidobacterium infantis and Bifidobacterium breve (cultures B651 and B655 of NIZO Food Research, respectively) were used to plot a standard curve from which the number of bifidobacteria in rat faeces could be calculated.

Before infection, fresh faecal samples were collected directly from the anus of animals and analysed for the number of enterobacteria and lactobacilli. Faecal enterobacteria were quantified by plating lofold dilutions in saline on Levine EMB Agar (Difco Laboratories, Detroit, Michigan, USA) and incubating aerobically overnight at $37^{\circ} \mathrm{C}$. Lactobacilli were quantified by plating on Rogosa Agar (Oxoid, Basingstoke, UK) and incubating in anaerobic jars (MART Microbiology, Lichtenvoorde, the Netherlands) at $37^{\circ} \mathrm{C}$ for three days. The detection limit of this method was $10^{2} \mathrm{CFU} / \mathrm{g}$ faecal wet weight.

To determine salmonella numbers in caecal contents seven days after infection, the caecum was excised and caecal contents were removed. The $\mathrm{pH}$ of the caecal contents was measured at $37^{\circ} \mathrm{C}$ and caecal tissue was weighed. Tenfold dilutions of caecal contents in saline were plated on Modified Brilliant Green Agar (Oxoid) and incubated aerobically overnight at $37^{\circ} \mathrm{C}$. The agar plates contained sulphamandelate (Oxoid) to suppress swarming bacteria such as proteus species. The detection limit of this method was $10^{2} \mathrm{CFU} / \mathrm{g}$ faecal wet weight.

\section{Biochemical analyses of faeces}

Total faecal lactic acid was measured using a colorimetric enzymatic kit (Boehringer Mannheim, Germany), as described previously. ${ }^{12}$ To measure calcium, faeces were treated with $50 \mathrm{~g} / \mathrm{l}$ trichloroacetic acid for one $\mathrm{h}$ at room temperature and centrifuged for two minutes at $14000 \mathrm{~g}$. The supernatants were diluted with $0.5 \mathrm{~g} / \mathrm{l} \mathrm{CsCl}$ and analysed by ICP-AES (Varian). To measure phosphate, dry ashed faeces was destructed $\left(15\right.$ minutes at $\left.180^{\circ} \mathrm{C}\right)$ with a perchloric acid $(70 \%)$ /hydrogen peroxide $(30 \%)$ mixture (5:1 vol/ vol, total volume $600 \mu \mathrm{l})$. Subsequently, samples were centrifuged for two minutes at $14000 \mathrm{~g}$. The supernatants were diluted with $0.5 \mathrm{~g} / \mathrm{l} \mathrm{CsCl}$ and analysed by ICP-AES (Varian).

Mucin was extracted from freeze dried faeces and quantified fluorimetrically, as described previously. ${ }^{12}$ Interfering oligosaccharides of dietary origin were removed by filtration (data not shown). Standard solutions of $\mathrm{N}$-acetylgalactosamine (Sigma, St Louis, Missouri, USA) were used to calculate the amount of oligosaccharide side chains liberated from mucins. Therefore, faecal mucins are expressed as $\mu \mathrm{mol}$ oligosaccharide equivalents.

\section{Analyses of faecal water}

Fresh faeces were freeze dried and reconstituted with double distilled water to obtain faecal water with a physiological osmolarity of $300 \mathrm{mosmol} / \mathrm{l}$. Samples were mixed, incubated for one hour at $37^{\circ} \mathrm{C}$, and subsequently centrifuged for one hour at $14000 \mathrm{~g}$ (Hettich, Micro-rapid 1306, Tuttlingen, Germany). Cytotoxicity of faecal water was determined with an erythrocyte assay, as previously described, ${ }^{15}$ and validated earlier with intestinal epithelial cells. ${ }^{16}$ Incubations were of physiological ionic strength (300 mosmol/l) and buffered at pH 7.0 (final $100 \mathrm{mmol} / \mathrm{l}$ 3-N-morpholino-propanesulfonic acid; Sigma) to prevent acid induced haemolysis.

\section{Analyses of urine samples}

Complete 24 hour urine samples were collected starting one day before infection until six days after infection. Oxytetracycline (1 mg; Sigma) was added to the urine collection vessels of the metabolic cages to prevent bacterial deterioration. The concentration of $\mathrm{NO}_{\mathrm{x}}$ (sum of nitrate and nitrite) was determined using a colorimetric enzymatic kit (No 1746081; Roche Diagnostics, Mannheim, Germany). Briefly, urinary nitrate is reduced to nitrite by nitrate reductase. Subsequently, nitrite reacts with sulphanilamide and $\mathrm{N}$-(1-naphthyl)-ethylene-diamine dihydrochloride, resulting in a red diazo dye, which was measured spectrophotometrically at $540 \mathrm{~nm}$.

\section{Statistical analysis}

Results are expressed as means (SEM). A commercially available package (Statistica 6.1; StatSoft Inc., Tulsa, Oklahoma, USA) was used for all statistics. We tested for differences between the low calcium/control, FOS, and inulin groups. In addition, we tested for differences between the high calcium groups and their low calcium counterparts. In case of normally distributed data, differences between means were tested for significance using a one way ANOVA, followed by Fisher's protected least significant difference test (two sided). Differences were considered statistically significant when $\mathrm{p}<0.05$. When data were not normally distributed, differences between means were tested for significance using a Kruskall-Wallis ANOVA, followed by the non-parametric Mann-Whitney $U$ test (two sided). Bonferroni correction was made for the number of comparisons $(n=6)$. Differences were considered statistically significant when $\mathrm{p}<0.05$.

\section{RESULTS}

\section{Animal growth and food intake}

One animal in the high calcium/FOS group was excluded from all study results because of oropharyngeal reflux of the salmonella suspension, resulting in pneumonia. Before infection, there were no differences in animal growth between the diet groups. Mean animal growth was 1.26 
Table 1 Effect of dietary fructo-oligosaccharides (FOS), inulin, and calcium on animal growth, caecal $\mathrm{pH}$, and caecum weight after infection $\dagger$

\begin{tabular}{lcll}
\hline & Growth (g/day) & Caecal pH & Caecal weight $(\mathbf{g})$ \\
\hline Low calcium & & & \\
Control & $1.4(0.2)$ & $7.2(0.2)$ & $1.2(0.1)$ \\
Inulin & $0.5(0.2)$ & $6.0(0.1)^{*}$ & $1.9(0.1)^{*}$ \\
FOS & $-0.6(0.5)^{*}$ & $6.5(0.3)^{*}$ & $2.1(0.1)^{*}$ \\
High calcium & & & \\
Control & $1.4(0.2)$ & $7.5(0.2)$ & $1.2(0.1)$ \\
Inulin & $0.7(0.5)$ & $7.0(0.3) \dagger$ & $1.8(0.1)$ \\
FOS & $0.6(0.3) \dagger$ & $6.8(0.2)$ & $1.7(0.1)$ \\
\hline
\end{tabular}

tResults are expressed as mean (SEM) $(n=7$ in the high calcium FOS group and $n=8$ in the other diet groups).

*Significantly different from the low calcium/control group $(p<0.05)$;

tsignificantly different from its low calcium counterpart $(p<0.05)$.

(0.07) g/day. However, after infection, animal growth was significantly reduced in the low calcium/FOS group (table 1). Calcium counteracted the infection induced impaired growth of the FOS group. Before infection, all animals consumed the provided $13 \mathrm{~g} /$ day, as intended. During the first week after infection, the low calcium/inulin and FOS groups consumed less than the control group although this was not significant (data not shown).

\section{Caecal and faecal parameters}

Both low calcium/inulin and FOS lowered caecal pH (table 1). Calcium counteracted this effect in the inulin group. Moreover, both low calcium/inulin and FOS increased caecal weight (table 1). Dietary calcium did not affect caecal weight.

Dietary prebiotics or calcium did not affect faecal bifidobacteria counts. However, low calcium/inulin and FOS did increase the number of lactobacilli in faeces (table 2). Dietary calcium increased faecal lactobacilli in the inulin and control group only. In addition, low calcium/inulin and FOS increased the number of enterobacteria in faeces (table 2). Dietary calcium decreased enterobacteria numbers in the inulin and FOS group. Salmonella infection did not affect the level of these bacterial genera in faecal samples collected after infection (data not shown).

Before infection, low calcium/inulin and FOS tended to increase faecal lactic acid excretion although this was not statistically significant (table 3). Calcium strongly increased daily faecal lactic acid excretion in all dietary groups. Both low calcium/inulin and FOS decreased daily faecal excretion of calcium and phosphate (table 3). As expected, daily faecal
Table 3 Effect of dietary fructo-oligosaccharides (FOS), inulin, and calcium on faecal lactate, calcium, and phosphate excretion before infection $\ddagger$

\begin{tabular}{llll}
\hline & $\begin{array}{l}\text { Lactate } \\
\text { ( } \mu \mathrm{mol} / \text { day) }\end{array}$ & $\begin{array}{l}\text { Calcium } \\
(\mu \mathrm{mol} / \text { day) }\end{array}$ & $\begin{array}{l}\text { Phosphate } \\
\text { ( } \mu \mathrm{mol} / \text { day) }\end{array}$ \\
\hline $\begin{array}{l}\text { Low calcium } \\
\text { Control }\end{array}$ & $2.4(0.3)$ & $109(13)$ & $113(8)$ \\
$\begin{array}{l}\text { Inulin } \\
\text { FOS }\end{array}$ & $6.9(1.6)$ & $28(3)^{*}$ & $64(6)^{*}$ \\
High calcium & $6.4(2.1)$ & $30(6)^{*}$ & $60(5)^{*}$ \\
Control & $9.4(2.6) \dagger$ & $766(30) \dagger$ & $468(40) \dagger$ \\
Inulin & $21.3(4.3) \dagger$ & $619(39) \dagger$ & $374(29) \dagger$ \\
FOS & $26.9(7.9) \dagger$ & $615(35) \dagger$ & $367(42) \dagger$ \\
\hline
\end{tabular}

flactic acid was measured using a colorimetric enzymatic kit. Calcium and phosphate were analysed by ICP-AES. Results are expressed as mean (SEM) ( $n=7$ in the high calcium FOS group and $n=8$ in the other diet groups).

*Significantly different from the low calcium/control group $(p<0.05)$;

†significantly different from its low calcium counterpart $(p<0.05)$.

output of these minerals was substantially higher in the high calcium groups.

In addition, low calcium/inulin and FOS increased the cytotoxicity of faecal water (fig l) and stimulated daily faecal mucin excretion in the low calcium groups before infection (fig 2). Both cytotoxicity and faecal mucin excretion were inhibited by dietary calcium.

\section{Colonisation and translocation of salmonella}

Both inulin and FOS increased salmonella numbers in caecal contents six days after infection (fig 3). Dietary calcium did not affect colonisation of salmonella in the caecum. Major differences were observed in the effects of low calcium/inulin and FOS on translocation of salmonella, as measured by the infection induced urinary $\mathrm{NO}_{\mathrm{x}}$ excretion in time (fig 4). Both low calcium/inulin and FOS increased urinary $\mathrm{NO}_{\mathrm{x}}$ excretion in time. At day 6 after infection, urinary $\mathrm{NO}_{\mathrm{x}}$ excretion was threefold higher in the low calcium/inulin group and fourfold higher in the low calcium/FOS group compared with the low calcium/control group. Dietary calcium inhibited translocation of salmonella to a large extend in the FOS group. Total infection induced urinary $\mathrm{NO}_{\mathrm{x}}$ excretion (corrected for baseline output) for the low calcium groups was 122 (12) $\mu \mathrm{mol} / 6$ days in the control group, 290 (59) $\mu \mathrm{mol} / 6$ days in the inulin group, and 448 (66) $\mu \mathrm{mol} / 6$ days in the FOS group. Total $\mathrm{NO}_{\mathrm{x}}$ excretion for the high calcium counterparts was 104 (13) $\mu \mathrm{mol} / 6$ days in the control group, 174

Table 2 Effect of dietary fructo-oligosaccharides (FOS), inulin, and calcium on faecal bifidobacteria, lactobacilli, and enterobacteria before infection $\ddagger$

\begin{tabular}{|c|c|c|c|}
\hline & \multirow{2}{*}{$\begin{array}{l}\text { Bifidobacteria } \\
\text { (No (log } 10 / g \text { wet faeces)) }\end{array}$} & Lactobacilli & Enterobacteria \\
\hline & & \multicolumn{2}{|c|}{ CFU (log $10 / g$ wet faeces) } \\
\hline \multicolumn{4}{|l|}{ Low calcium } \\
\hline Control & $9.5(0.1)$ & $5.1(0.4)$ & $7.6(0.1)$ \\
\hline Inulin & $9.8(0.1)$ & $6.6(0.4)^{*}$ & $8.8(0.1)^{*}$ \\
\hline FOS & $9.9(0.2)$ & $7.1(0.4)^{*}$ & $9.0(0.1)^{*}$ \\
\hline \multicolumn{4}{|c|}{ High calcium } \\
\hline Control & $8.9(0.1) \dagger$ & $6.7(0.2) \dagger$ & $7.4(0.2)$ \\
\hline Inulin & $10.1(0.1)$ & $7.5(0.5) \dagger$ & $7.7(0.3) \dagger$ \\
\hline FOS & $10.2(0.1)$ & $7.9(0.2)$ & $7.7(0.2) \dagger$ \\
\hline
\end{tabular}

$\ddagger$ Bifidobacteria were specifically quantified by real time quantitative polymerase chain reaction. Lactobacilli and enterobacteria were quantified by standard culturing on appropriate agar plates.

Results are expressed as mean (SEM) ( $n=7$ in the high calcium FOS group and $n=8$ in the other diet groups). *Significantly different from the low calcium/control group $(p<0.05)$; †significantly different from its low calcium counterpart $(\mathrm{p}<0.05)$.

$\mathrm{CFU}$, colony forming units. 


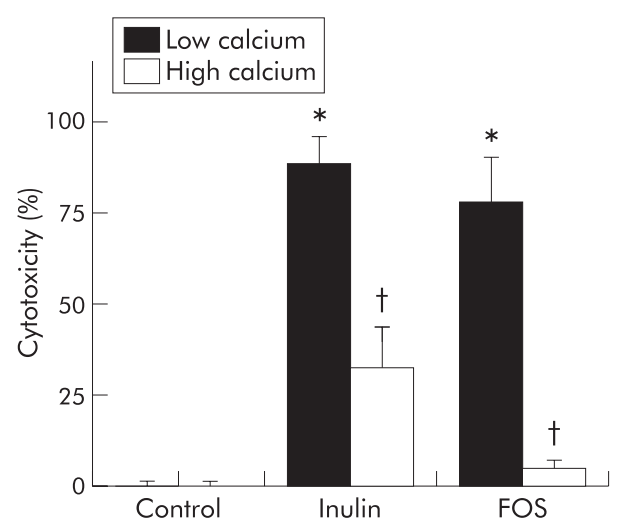

Figure 1 Effects of dietary inulin, fructo-oligosaccharides (FOS), and calcium on the cytotoxicity of faecal water of rats before infection. Cytotoxicity was determined using a haemolysis assay. Results are expressed as mean (SEM) ( $n=7$ in the high calcium FOS group and $n=8$ in the other diet groups). *Significantly different from the low calcium/ control group $(p<0.05)$; †significantly different from its low calcium counterpart $(p<0.05)$.

(40) $\mu \mathrm{mol} / 6$ days in the inulin group, and 217 (41) $\mu \mathrm{mol} /$ 6 days in the FOS group.

\section{DISCUSSION}

This study showed that inulin and FOS significantly stimulated intestinal colonisation and translocation of salmonella to extraintestinal sites. These adverse effects were largely inhibited by dietary calcium phosphate.

The general opinion is that inulin and FOS may increase resistance to intestinal infections by selectively stimulating the growth and/or activity of one or a limited number of bacteria in the colon. ${ }^{2}$ Indeed, previous studies showed that inulin and FOS stimulated intestinal bifidobacteria and lactobacilli in rats and human. ${ }^{34}{ }^{17}$ However, in the present study, no effect of inulin or FOS on faecal bifidobacteria was observed. An explanation could be that when initial bifidobacteria counts are high to start with, a further increase in their numbers might not be demonstrable. ${ }^{10}{ }^{18}$ Although lactobacilli were stimulated in the present study by inulin and FOS, our results, as well as those of others, do not support the concept of selective stimulation because intestinal enterobacteria, which are associated with gut derived septicaemia, ${ }^{19}$ were also stimulated. ${ }^{20} 21$ The endogenous microflora is known to be important for host resistance. However, the effects of inulin and FOS on resistance to intestinal bacterial infections have rarely been investigated in in vivo studies. The few previously published studies showed inconsistent effects of oligosaccharides on colonisation of salmonella. ${ }^{22-25}$ In the present study, inulin and FOS increased salmonella colonisation in the caecum, despite stimulation of the intestinal microflora. These results do not confirm the results obtained in a previous study of our group. However, there is one important difference: in the previous study, ${ }^{7}$ salmonella was administered to animals in a fed state while in the present study the salmonella suspension was given after an overnight fast (that is, on an acidic empty stomach). This may have provoked an acid tolerance response in salmonella ${ }^{26}{ }^{27}$ which may have increased its virulence and subsequent survival within the caecum and colon. ${ }^{26}{ }^{27}$ Apart from the increase in colonisation, both prebiotics markedly stimulated salmonella translocation to extraintestinal sites, as measured by urinary excretion of $\mathrm{NO}_{\mathrm{x}}$ metabolites. Urinary $\mathrm{NO}_{\mathrm{x}}$ is a sensitive and quantitative biomarker of intestinal bacterial translocation ${ }^{28}$ which correlates with organ cultures $^{29}$ and severity of systemic infectious diseases in rats and

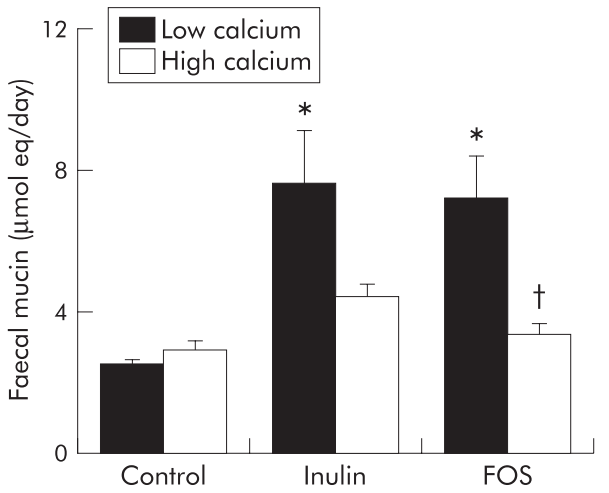

Figure 2 Effects of dietary inulin, fructo-oligosaccharides (FOS), and calcium on daily faecal mucin excretion of rats before infection. Mucins were measured fluorimetrically and expressed as $\mu \mathrm{mol}$ oligosaccharide equivalents. Results are expressed as mean (SEM) ( $n=7$ in the high calcium FOS group and $\mathrm{n}=8$ in the other diet groups). *Significantly different from the low calcium/control group $(p<0.05)$; †significantly different from its low calcium counterpart $(p<0.05)$.

humans. ${ }^{30-32}$ The increased colonisation and translocation of salmonella in the present study, concomitant with decreased animal growth after infection, indicates that the infection was worse in the low calcium/inulin and FOS groups. These data confirm the results of our previous studies in which FOS increased translocation of salmonella. ${ }^{67}$

Why do inulin and FOS increase translocation of salmonella? Fermentation of both inulin and FOS results in the production of organic acids in the distal gut, ${ }^{33}$ indicated by the high faecal lactate concentration and the low caecal pH. Accumulation of organic acids and other fermentation metabolites may lead to irritation and impairment of the mucosal barrier.8 ${ }^{934}$ The intestinal mucosa responds to these irritating components by increasing mucus excretion. ${ }^{35} 36$ Indeed, inulin and FOS increased faecal mucin excretion in the present study. In addition, previous studies showed that fermentable fibres increase faecal mucin excretion. ${ }^{37}{ }^{38}$ Thus rapid fermentation of FOS and inulin may impair the mucosal barrier in the distal gut. Translocation of salmonella is believed to occur through ileal Peyer's patches but this issue is still debated..$^{39}$ Impairment of the barrier by rapid fermentation of inulin and FOS might expand the possibilities for salmonella to translocate in the distal gut, para- or

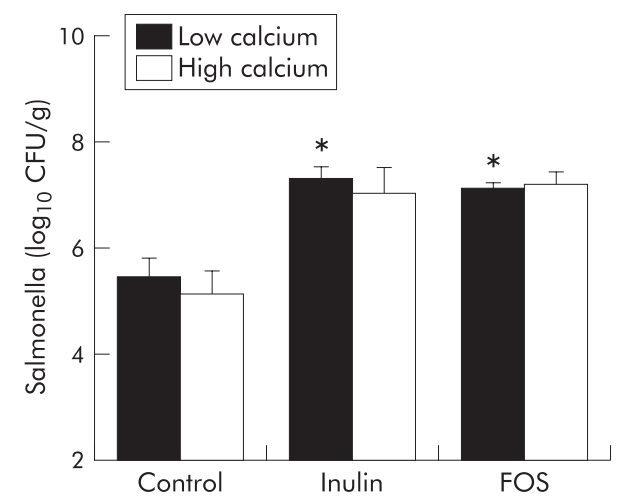

Figure 3 Effects of dietary inulin, fructo-oligosaccharides (FOS), and calcium on salmonella numbers in caecal contents of rats six days after oral administration of $2 \times 10^{9}$ colony forming units (CFU) of Salmonella enterica serovar Enteritidis. Salmonella was cultured aerobically on modified brilliant green agar. Results are expressed as mean (SEM) ( $n=7$ in the high calcium FOS group and $n=8$ in the other diet groups). *Significantly different from the low calcium/control group $(p<0.05)$. 

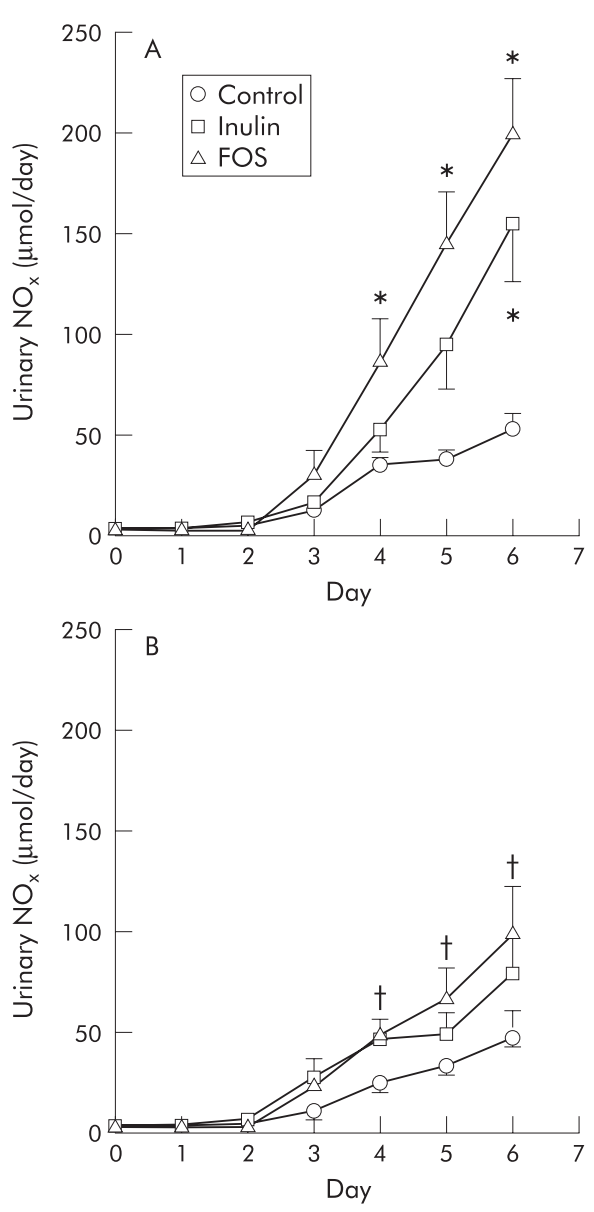

Figure 4 Urinary sum of nitrate and nitrite $\left(\mathrm{NO}_{x}\right)$ excretion in the control, inulin, and fructo-oligosaccharide (FOS) groups after an oral challenge with $2 \times 10^{9}$ colony forming units of Salmonella enterica serovar Enteritidis on day 0 in the (A) low calcium groups and (B) high calcium groups. Results are expressed as mean (SEM) $(n=7$ in the high calcium FOS group and $n=8$ in the other diet groups). *Significantly different from the low calcium/control group at that time point $(p<0.05)$; tsignificantly different from its low calcium counterpart at that time point $(p<0.05)$.

transcellularly. ${ }^{40}$ Surprisingly, the effects of inulin and FOS were similar. Probably both prebiotics were equally rapidly fermented in the distal gut resulting in damage to the mucosal barrier. In addition, although organic acids inhibit growth of salmonella in vitro, prebiotic induced alterations in organic acid concentrations may increase salmonella virulence $^{41} 42$ and hence increase translocation.

Most adverse effects of inulin and FOS were inhibited by dietary calcium. Calcium forms an insoluble complex with phosphate in the upper small intestine. ${ }^{11}$ Fermentation of inulin and FOS results in a considerable production of organic acids and hence acidification of gut contents. This can subsequently be counteracted by solubilisation of the calcium phosphate complex. However, when the dietary calcium phosphate supply is limited, the amounts of insoluble calcium phosphate may be insufficient to counteract acidification. ${ }^{9}$ Moreover, the present study and previous studies ${ }^{43}{ }^{44}$ show that both inulin and FOS stimulate calcium absorption. Subsequently, less calcium phosphate will be available within the intestinal lumen to counteract the adverse effects of acidic fermentation.

Another mechanism by which calcium may improve the mucosal barrier is precipitation of cytotoxic components within the intestinal lumen. The amorphous calcium phosphate complex precipitates cytotoxic components in the intestinal lumen, which reduces epithelial cell damage $e^{45}$ and increases resistance towards salmonella translocation. Indeed, dietary calcium inhibited the cytotoxicity of faecal water, induced by inulin and FOS. The cytotoxicity assay was performed in a buffer of neutral $\mathrm{pH}$, precluding simple acid induced lysis. Thus calcium phosphate increases the buffering capacity of the intestinal lumen and has cytoprotective effects, which may preserve the mucosal barrier. ${ }^{12}$

In conclusion, the present study shows that FOS and inulin impair resistance to salmonella infections in rats. This effect is likely due to the rapid production of fermentation metabolites and subsequent impairment of the mucosal barrier. Dietary calcium phosphate inhibited the adverse effects of acidic fermentation and largely prevented damage to the intestinal barrier. The results of the present study await verification in other controlled animal and human studies. However, considering the current interest in health foods supplemented with fermentable fibres, concern is warranted.

\section{ACKNOWLEDGEMENTS}

The authors wish to thank Wim van Doesburg for analytical analysis and the biotechnicians working at the Small Animal Centre of Wageningen University for expert biotechnical assistance.

\section{Authors' affiliations}

S J M Ten Bruggencate, I M J Bovee-Oudenhoven, M L G LettinkWissink, M B Katan, R Van der Meer, Nutrition and Health Program, Wageningen Centre for Food Sciences/NIZO Food Research, Ede, the Netherlands

\section{REFERENCES}

1 Kasper $\mathbf{H}$. Protection against gastrointestinal diseases - present facts and future developments. Int J Food Microbiol 1998;41:127-31.

2 Gibson GR, Roberfroid MB. Dietary modulation of the human colonic microbiota: introducing the concept of prebiotics. J Nutr 1995;125:1401-12.

3 Kleessen B, Hartmann L, Blaut M. Oligofructose and long-chain inulin: influence on the gut microbial ecology of rats associated with a human faecal flora. Br J Nutr 2001;86:291-300.

4 Gibson GR, Beatty ER, Wang X, et al. Selective stimulation of bifidobacteria in the human colon by oligofructose and inulin. Gastroenterology 1995; 108:975-82.

5 Orrhage K, Nord CE. Bifidobacteria and lactobacilli in human health. Drugs Exp Clin Res 2000;26:95-111.

6 Ten Bruggencate SJM, Bovee-Oudenhoven IMJ, Lettink-Wissink MLG, et al Dietary fructo-oligosaccharides dose-dependently increase translocation of salmonella in rats. J Nutr 2003;133:2313-18.

7 Bovee-Oudenhoven IMJ, Ten Bruggencate SJM, Lettink-Wissink MLG, et al. Dietary fructo-oligosaccharides and lactulose inhibit intestinal colonisation but stimulate translocation of salmonella in rats. Gut 2003;1 1:1572-8.

8 Argenzio RA, Meuten DJ. Short-chain fatty acids induce reversible injury of porcine colon. Dig Dis Sci 1991;36:1459-68.

9 Rémésy C, Levrat MA, Gamet L, et al. Cecal fermentations in rats fed oligosaccharides (inulin) are modulated by dietary calcium level. Am J Physio 1993;264:G855-62.

10 Roberfroid MB, Van Loo JA, Gibson GR. The bifidogenic nature of chicory inulin and its hydrolysis products. J Nutr 1998;128:11-19.

11 Govers MJ, Van der Meer R. Effects of dietary calcium and phosphate on the intestinal interactions between calcium, phosphate, fatty acids, and bile acids. Gut 1993;34:365-70.

12 Bovee-Oudenhoven IM, Termont DS, Heidt PJ, et al. Increasing the intestinal resistance of rats to the invasive pathogen Salmonella enteritidis: additive effects of dietary lactulose and calcium. Gut 1997;40:497-504.

13 Reeves PG, Nielsen FH, Fahey GC jr. AIN-93 purified diets for laboratory rodents: final report of the American Institute of Nutrition ad hoc writing committee on the reformulation of the AIN-76A rodent diet. J Nutr 1993; 123:1939-51.

14 Requena T, Burton J, Matsuki T, et al. Identification, detection, and enumeration of human bifidobacterium species by PCR targeting the transaldolase gene. Appl Environ Microbiol 2002;68:2420-7.

15 Bovee-Oudenhoven I, Termont D, Dekker R, et al. Calcium in milk and fermentation by yoghurt bacteria increase the resistance of rats to Salmonella infection. Gut 1996:38:59-65.

16 Lapré JA, Termont DS, Groen AK, et al. Lytic effects of mixed micelles of fatty acids and bile acids. Am J Physiol 1992;263:G333-7.

17 Bouhnik Y, Flourie B, D'Agay-Abensour L, et al. Administration of transgalacto-oligosaccharides increases fecal bifidobacteria and modifies colonic fermentation metabolism in healthy humans. J Nutr 1997;127:444-8. 
18 Tuohy KM, Kolida S, Lustenberger AM, et al. The prebiotic effects of biscuits containing partially hydrolysed guar gum and fructo-oligosaccharides - a human volunteer study. Br J Nutr 2001;86:341-8.

19 Kayama S, Mitsuyama M, Sato N, et al. Overgrowth and translocation of Escherichia coli from intestine during prolonged enteral feeding in rats. J Gastroenterol 2000;35:15-19.

20 Sakai K, Aramaki K, Takasaki M, et al. Effect of dietary short-chain fructooligosaccharides on the cecal microflora in gastrectomized rats. Biosci Biotechnol Biochem 2001;65:264-9.

21 Oli MW, Petschow BW, Buddington RK. Evaluation of fructooligosaccharide supplementation of oral electrolyte solutions for treatment of diarrhea: recovery of the intestinal bacteria. Dig Dis Sci 1998;43:138-47.

22 Chambers JR, Spencer JL, Modler HW. The influence of complex carbohydrates on Salmonella typhimurium colonization, $\mathrm{pH}$, and density of broiler ceca. Poult Sci 1997;76:445-51.

23 Oyarzabal OA, Conner DE. Application of direct-fed microbial bacteria and fructooligosaccharides for salmonella control in broilers during feed withdrawal. Poult Sci 1996;75:186-90.

24 Asahara T, Nomoto K, Shimizu M, et al. Increased resistance of mice to Salmonella enterica serovar Typhimurium infection by synbiotic administration of Bifidobacteria and trangalactosylated oligosaccharides. J Appl Microbiol 2001;91:985-96.

25 Letellier A, Messier S, Lessard L, et al. Assessment of various treatments to reduce carriage of Salmonella in swine. Can J Vet Res 2000;64:27-31.

26 Gahan CG, Hill C. The relationship between acid stress responses and virulence in Salmonella typhimurium and Listeria monocytogenes. Int J Food Microbiol 1999:50:93-100.

27 Kwon YM, Ricke SC. Induction of acid resistance of Salmonella typhimurium by exposure to short-chain fatty acids. Appl Environ Microbiol 1998;64:3458-63.

28 Oudenhoven IM, Klaasen HL, Lapre JA, et al. Nitric oxide-derived urinary nitrate as a marker of intestinal bacterial translocation in rats. Gastroenterology 1994; 107:47-53.

29 Bovee-Oudenhoven IM, Termont DS, Weerkamp AH, et al. Dietary calcium inhibits the intestinal colonization and translocation of Salmonella in rats. Gastroenterology 1997;113:550-7.

30 Charmandari E, Meadows N, Patel $M$, et al. Plasma nitrate concentrations in children with infectious and noninfectious diarrhea. J Pediatr Gastroenterol Nutr $2001 ; 32: 423-7$.
31 Sprong RC, Hulstein MF, Van der Meer R. Quantifying translocation of Listeria monocytogenes in rats by using urinary nitric oxide-derived metabolites. Appl Environ Microbiol 2000;66:5301-5.

32 Forte $\mathbf{P}$, Dykhuizen RS, Milne $E$, et al. Nitric oxide synthesis in patients with infective gastroenteritis. Gut 1999;45:355-61.

33 Campbell JM, Fahey GC jr, Wolf BW. Selected indigestible oligosaccharides affect large bowel mass, cecal and fecal short-chain fatty acids, $\mathrm{pH}$ and microflora in rats. J Nutr 1997;127:130-6.

34 Levrat MA, Rémésy $C$, Demigné $C$. High propionic acid fermentations and mineral accumulation in the cecum of rats adapted to different levels of inulin. J Nutr 1991;121:1730-7.

35 Barcelo A, Claustre J, Moro F, et al. Mucin secretion is modulated by luminal factors in the isolated vascularly perfused rat colon. Gut 2000;46:218-24.

36 Klinkspoor JH, Mok KS, Van Klinken BJ, et al. Mucin secretion by the human colon cell line LS174T is regulated by bile salts. Glycobiology 1999;9:13-19.

37 Satchithanandam S, Klurfeld DM, Calvert RJ, et al. Effects of dietary fibers on gastrointestinal mucin in rats. Nutr Res 1996;16:1163-77.

38 Cabotaje LM, Shinnick FL, Lopez-Guisa JM, et al. Mucin secretion in germfree rats fed fiber-free and psyllium diets and bacterial mass and carbohydrate fermentation after colonization. Appl Environ Microbiol 1994;60:1302-7.

39 Hughes EA, Galan JE. Immune response to Salmonella: location, location, location? Immunity 2002;16:325-8.

40 Kops SK, Lowe DK, Bement WM, et al. Migration of Salmonella typhi through intestinal epithelial monolayers: an in vitro study. Microbiol Immunol 1996;40:799-811.

41 Lawhon SD, Maurer R, Suyemoto M, et al. Intestinal short-chain fatty acids alter Salmonella typhimurium invasion gene expression and virulence through BarA/SirA. Mol Microbiol 2002;46:1451-64.

42 Durant JA, Corrier DE, Ricke SC. Short-chain volatile fatty acids modulate the expression of the hilA and invF genes of Salmonella typhimurium. J Food Prot 2000:63:573-8.

43 Younes H, Coudray C, Bellanger J, et al. Effects of two fermentable carbohydrates (inulin and resistant starch) and their combination on calcium and magnesium balance in rats. Br J Nutr 2001;86:479-85.

44 van den Heuvel EG, Muys T, van Dokkum W, et al. Oligofructose stimulates calcium absorption in adolescents. Am J Clin Nutr 1999:69:544-8.

45 Govers MJ, Termont DS, Van der Meer R. Mechanism of the antiproliferative effect of milk mineral and other calcium supplements on colonic epithelium. Cancer Res 1994;54:95-100. 